\title{
Regulating Damage Clauses in Labor Contracts
}

\author{
Gerd Muehlheusser ${ }^{1}$
}

June 10, 2002

\footnotetext{
${ }^{1}$ University of Bonn and IZA. Contact Address: University of Bonn, Department of Economics, Wirtschaftspolitische Abteilung, Adenauerallee 24-42, D-53113 Bonn. gerd.muehlheusser@wiwi.uni-bonn.de

Financial support from the Deutsche Forschungsgemeinschaft (DFG) is gratefully acknowledged. I am very grateful to Eberhard Feess, Urs Schweizer and Andreas Roider for many helpful discussions.
} 


\begin{abstract}
We analyze the role of damage clauses in labor contracts in which the worker may desire to work for another firm. We show that the initial contracting parties have an incentive to stipulate excessive damages in the contract which leads to ex post inefficiencies for some states of the world. We show that the frequently used rule of putting an upper bound on enforceable damages is welfare improving. Thereby, the crucial role of the worker's outside option is stressed. The result obtained are used to explain why binding long term contracts are frequently prohibited in labor law.
\end{abstract}

Keywords: Damage Clauses, Penalty Doctrine, Asymmetric Information, Labor Contracts

JEL-Classification: K12, K31, M12 


\section{Introduction}

In many countries, labor markets are regulated in the sense that contracts which cover a considerable period of time and which cannot be unilaterally terminated are prohibited. ${ }^{1}$ In Germany for example, it is possible to sign temporary employment contracts which can be terminated before expiration only if both parties agree, i.e. temporary employment contracts are in principle exempt from the contractual notice of termination in German Labor Law (§620 Ab.1 BGB). However, this only holds if the temporary contract lasts no longer than 5 years, in which case the worker can always unilaterally terminate the relationship after a period of notice of 6 month ( $\$ 624$ BGB). As another example, according to a new legislation in European professional soccer, the maximum length for which contract between players and their clubs can be signed is also five years. The main argument why these kinds of regulations are frequently believed to be justified is twofold: First, long term contracts tie workers and their employer together and it may become difficult for one of the parties to convince the other party to agree to a separation in case that there is some ex ante unforeseen contingency which induces this party to prefer separation (this is sometimes called the "slavery argument"). Specifically, in German Labor Law it is argued that workers should to be protected from making "mistakes" by not enabling them to commit to an excessive period of time to one single employer, because job satisfaction is supposed to constitute an important ingredient of a worker's well-being. The second argument is concerned with the ex post efficient allocation of workers in the labor market. It is argued that if a worker and an employer are tied together by means of a long term contract, then this could prevent that the worker will always work for the firm in which his productivity is maximum, because either the firm does not always agree to a separation whenever it is efficient or because the worker refuses to terminate his job. Clearly, these regulations constitute restrictions on the freedom of contract, because they disable parties to sign a binding long term contract.

From an economic point of view, one implication of long term contracts is that the breached-against party, the firm say, is entitled to damages if the worker intends to work for another firm and therefore wishes to terminate the initial relationship unilaterally.

\footnotetext{
${ }^{1}$ Of course, any contract can be terminated if all parties to a contract agree to do so.
} 
These damages can either be included in the initial labor contract (liquidated damages) or they can be assigned by a court using standard breach remedies. It seems reasonable to assume that the damage payment, either as specified in the contract of agreed on in renegotiations, is (at least weakly) increasing in the remaining length of the initial contract. This simply reflects the notion that "waiting is costly" for the new firm (and possibly also for the worker). ${ }^{2}$ In this sense, restricting the maximum contract length can also be interpreted as restricting the maximum level of damage clauses for breach of contract which can be stipulated in a contract. ${ }^{3}$

One main argument from the economic literature against these kinds of restrictions is that absent frictions like private information, costly bargaining or wealth constraints, Coasian bargaining will always lead to an ex post efficient allocation of a worker since all parties (i.e. the worker, the initial firm and the new firm) can be made better off by agreeing on a transfer of the worker if his productivity is higher in the new firm, independent of whether he has a binding contract with the old firm or not. Thus there does not seem to be a need for restrictions. Clearly, the conditions under which the Coase theorem seems a reasonable approximation to reality differ among different segments of the labor market: in this paper, private information will prevent that Coasian bargaining could lead to ex post efficiency.

Moreover, the theoretical literature has shown that the initial parties to a contract can restrict the expected payoff of third parties by choosing high damage clauses. This may reduce social welfare, since the damage clause could prevent the transfer of the worker to the new firm for some states of the world for which this would be efficient.

In our model, it is assumed that after the initial contract has been signed, the worker receives additional information which specifies in which of two firms he would prefer to work. On the other hand, neither of the firm knows the worker's preferences while signaling or screening devices are not available. In such a model we find that in equi-

\footnotetext{
${ }^{2}$ This notion is for example used in Aghion and Bolton (1987). Moreover, it drops out as an equilibrium feature of a renegotiation game in which the worker simultaneously bargains with both firms in the form Nash-Bargaining together with the reasonable assumption that the initial form gets a higher share of the surplus when it can prevent the transfer in teh threat point, see Burguet, Caminal, and Matutes (2001) and Feess and Muehlheusser (2002).

${ }^{3}$ Therefore, restricting the maximum contract length is akin to the famous "penalty doctrine" in US common law, under which excessive damages clauses are not enforced by the court (see for example Uniform Commercial Code § 2-718 (1978)).
} 
librium, there will be ex post inefficiencies in the sense that the worker will not always be transferred whenever it is efficient to do so. The reason is that when negotiating the initial contract, the worker and the initial firm and the worker have a joint incentive to stipulate excessive damage clauses in order to reduce the expected profit of the new firm. Since ex post efficiency will not be achieved, this rent-seeking behavior prevents efficient transfers for some realizations of the worker's preferences. It is shown that the extent of the inefficiency depends crucially on the level of the worker's outside option, which we use as a proxy for the bargaining power of the worker at the initial contracting stage.

The question then arises, whether a social planner can improve upon the outcome stipulated by the private parties by setting an upper bound on the level of the damage clause which is enforceable in court and can therefore contractually agreed on. We provide a very strong argument for restricting the freedom of contract in this case by showing that the regulator can always induce a higher level of expected social welfare independent of how the surplus is split between the worker and the initial firm at the initial contracting stage.

Contrary to the seminal literature by Shavell (1980) and Rogerson (1984), in which the joint surplus to be shared among the initial parties to a contract coincides with the social surplus, in the presence of externalities, the use of contracts and, in particular, the use of damage clauses as a means to extract rents from a third party has been analyzed in the following literature:

Diamond and Maskin (1979) analyze a search model in which agents engage in searching suitable partners to carry out projects, where the value of the project depends on the quality of the match. Once a partner is found, a contract is signed. However, agents can continue to search for a better match. In case of finding a better match, this leads to the possibility that one of the partners (or both) wants to terminate the relationship. The parties may put a damage clause in their initial contract in case that breach occurs. They find that since the surplus is shared equally in each partnership, there is an incentive to stipulate high damages in the initial contract because this will increase the payoff in the new partnership. As they note on, "the rationale for these contracts is solely to 'milk' future partners for damage payments" (Diamond and Maskin (1979, p. 294)). As a result, liquidated damages will always be higher than compensatory damages. Whether this is 
desirable from s social point of view crucially depends on the matching technology.

In a different context, Aghion and Bolton (1987) analyze the role of contracts in the context of entry prevention. In their model, there is an incumbent seller $S$ which faces the threat of entry by an alternative seller $E$ into the market which consists of a single buyer $B$. There is no investment. In the initial contract, apart from the trading price $p, B$ and $S$ can again stipulate a damage clause $d$ which $B$ has to pay if chooses to buy from $E$ in case $E$ enters the market. If $E$ enters the market, then $B$ and $E$ compete in Bertrand competition for the buyer. This implies that $E$ expects strictly positive profits for some realizations of his cost parameter $\theta$ which is, in analogy to Shavell (1980), unknown ex ante but becomes revealed after the initial contract is signed, so that the breach decision by $B$ is under perfect information. It is shown that it is optimal for $B$ and $S$ to stipulate a damage clause which prevents entry for some realizations of $\theta$ (but not for all). The reason is that they act as a "monopolist" against $E$ and therefore choose a high level of $d$ to reduce the expected profit of $E$, since this will force $E$ to offer a lower price to $B$. Since Aghion and Bolton (1987) do not allow for renegotiation of the initial contract, in doing so, $B$ and $S$ create a social cost in form of an ex post inefficiency for some states of the world because the good is produced by $S$ although $E$ would be the sufficient supplier.

The paper by Chung (1992) extends the model of Aghion and Bolton (1987) by introducing specific investment and therefore allows to analyze the role of liquidated damages in a more general framework (while still not allowing for renegotiation of the initial contract). It also analyzes the role of standard (court-imposed) breach remedies, and is therefore also an extension of Shavell (1980) by introducing a third party with market power in which case this party's payoff is directly affected by the terms of the initial contract. The role of liquidated damages now becomes crucial and is consequently analyzed in the "Freedom of Contract Rule" $(F C)$ in which any stipulated damage clause is enforced by the court. Under rule $E D$, stipulated damages are ignored, and expectation damages are awarded by the court. The third rule considered is the "Penalty Doctrine" $(P D)$ under which the court puts an upper bound on enforceable damages. In particular, it is assumed that this upper bound is given by the damages under the ED rule. ${ }^{4}$

\footnotetext{
${ }^{4}$ This is motivated by the long standing debate as to which level damages clauses should be enforceable and from which level on they should be considered as "penalties" and therefore void.
} 
The setup of the model is that $S$ and $B$ sign a contract $(p, d)$. Afterwards, $B$ invests to enhance his valuation for the good. Then a new buyer $E$ enter the scene who learns his valuation for the good after $B$ 's investment decision and announces a price for which he would like to buy the good from $S$. Then $S$ decides whether to supply $B$ or $E$. Renegotiation of the initial contract is excluded. The main result in our context, however is that under rule $F C$, the initial contracting parties $B$ and $S$ will always choose a damage clause which is inefficiently high from a social point of view. The reason is again a rent seeking motive, since the damage clause acts as a commitment device for conceding a lower share of the expected surplus to $E$. Since there is no renegotiation, there will be an inefficiently low level of switching. In analogy to Shavell (1980) and Rogerson (1984), it is shown that under rules $E D$ and $P D, B$ has an incentive to overinvest, but that this incentive is lower under rule $P D$. Therefore, rule $P D$ weakly dominates rule $E D$. The welfare comparison with rule $F C$ is not unambiguous, since under rule $F C$, breach occurs less often than would be socially efficient, while rule $P D$ induces overinvestment.

Contrary to Chung (1992), although in a different context, in the present paper, the maximum level of enforceable damages is endogenously derived here while it is exogenously given by the expectation damages in Chung (1992). Moreover, this also contributes to the fact that concerning the welfare comparison, the regulator can always improve on the outcome induced by the parties to the contract, while the comparison between the $F C$ rule and the $P D$ rule was ambiguous in Chung (1992). ${ }^{5}$

Spier and Whinston (1995) analyze a model similar to Chung (1992) but also allow for renegotiation of the initial contract, which implies that the breach decision will always be efficient. Contrary to Chung (1992), it is the seller who invests in reducing the cost of providing the good to $B$, i.e. $c(I)$. The cost of the third party $E$ is realized after the investment is carried out. The interesting case arises again, when $E$ has some market power which is modeled by assuming that he can make a take-it-or-leave-it offer to $B$. Their main point is to show that allowing for investment and renegotiation re-establishes the basic result by Aghion and Bolton (1987) that the initial parties to sign socially

\footnotetext{
${ }^{5} \mathrm{Of}$ course, another factor which contributes to this fact is that the present model does not analyze investment incentives.
} 
inefficient contracts in order to extract rents from $E .{ }^{6}$ As was shown above, this argument was no longer valid for the case of renegotiation alone without investment. In their framework, $B$ and $S$ have a joint incentive to induce excessive investment by $S$, because this increases their joint return not only in those cases in which $S$ is the efficient supplier of the good, but also when $E$ is the efficient producer, since he has to lower the price in order to make the sale. Since the social planner only cares about the first effect, this would lead to overinvestment. However, Spier and Whinston (1995) show how the court can induce the first best outcome by setting a damage rule, the "efficient expectation damage $(E E D)$ ". Contrary to Spier and Whinston (1995), one point of the present paper is to argue that ex post inefficiencies matter in the labor market. Therefore, renegotiation is excluded in our model. However, as will become clear, the renegotiation game would have to take place under asymmetric information so that we would expect ex post inefficiency even if renegotiation was possible. ${ }^{7}$

Most recently, Posner and Triantis (2001) analyze the role and desirability of convenants not to compete (CNCs) which disallow a worker $W$ to compete against his employer $F$ or to work for a competitor $E$. CNCs can be more "fine-tuned" than specific performance since it enable to permit the worker at least to work for some alternative employers while not for all. Drawing on an earlier contribution by Rubin and Shedd (1981), they argue that the desirability off CNCs depends crucially on whether renegotiation of the initial contract is possible or not: If renegotiation is possible, then the role of $\mathrm{CNCs}$ is akin to the role of liquidated damages namely to extract rents from third parties. As a result, enforcement of CNCs will lead to excessive incentives to carry out specific investments. Moreover, they stress the role of CNCs for fostering investment incentives in general skills, because the CNC gives the initial employer a higher stake in the renegotiation game which increase his investment incentives.

This paper is organized as follows: The basic model is set up in section 2 . The scenario in which any damage clause is assumed to be enforceable is analyzed in section

\footnotetext{
${ }^{6}$ See also Chung (1995).

${ }^{7}$ This is a standard result in the meachnism design literature by Myerson and Satterthwaite (1983), which states that in a framework of asymmetric information, it is not possible to find a mechanism which leads to the ex post efficient solution for all states of the without violating the participation constraint of at least one party (see also Schweizer (1999)).
} 
3, while section 4 considers the case in which a regulator imposes an upper bound on the enforceable damage payments. In section 5 , the results form both scenarios are compared while section 6 discusses the main assumptions and concludes.

\section{The basic model}

We consider the contracting problem between a firm and a worker (both risk-neutral) in which the worker can either work for the firm with productivity $\beta \in \Re^{+}$or choose his outside option which yields reservation utility $U \in[0, \bar{U}]$. The firm, which has a reservation payoff of zero, is able to make a take-it-or-leave-it offer for a contract $\Omega=\left(w_{I}, r\right)$ which specifies a wage rate $w_{I} \in \Re_{0}^{+}$and a damage clause $r \in \Re$ which the worker has to pay if he chooses not to work for the firm after the contract has been signed. Thus, although any level of $r$ is assumed to be feasible, negative wages are not permitted. For instance, this might be due to the fact that the worker cannot commit ex ante to work for a negative wage. ${ }^{8}$ The values of the outside options of the worker and the firm, respectively are commonly known.

Denote the acceptance decision by the worker concerning the initial contract by $D_{I}(\Omega, U) \in\{0,1\}$. If he rejects the initial offer $\left(D_{I}=0\right)$, the game ends and the worker and the firm earn payoffs of $U$ and 0 , respectively. If he accepts it $\left(D_{I}=1\right)$, a new firm enters the scene. In order to distinguish both firms, we refer to the initial firm as "firm $I$ " and to the new firm as "firm $E$ ". The worker's productivity in firm $E$ is also $\beta$. From the worker's point of view, however, both firms differ with respect to a private benefit $b_{k}$ he receives when working for firm $k \in\{I, E\} .{ }^{9}$ The private benefit when working for firm $I$ is normalized to zero, i.e. $b_{I} \equiv 0$. The private benefit when working for firm $E$, $b_{E}$, is a random variable which is distributed in the interval $[-a, a]$ with $a>0$, according to a distribution function $F\left(b_{E}\right)$ with positive continuous density $f\left(b_{E}\right)$ and $f^{\prime}\left(b_{E}\right) \geq 0$. The expected value of $b_{E}$ is zero, i.e. $\int_{-a}^{a} b_{E} f\left(b_{E}\right) d b_{E}=0$.

The preference parameter $b_{E}$ is private information to the worker, which he learns after the initial contract with firm $I$ has been signed. The distribution $F\left(b_{E}\right)$ is common

\footnotetext{
${ }^{8}$ This assumption will be discussed in more detail in section 6 .

${ }^{9}$ The case where the worker incurs effort costs when working for either firm is completely analogous.
} 
knowledge among all parties.

After the worker has learned his type, firm $E$ may want to hire the worker by offering a wage $w_{E} \in \Re_{0}^{+}$in form of a take-it-or-leave-it offer. The acceptance decision of the worker in this case is denoted by $D_{E}\left(w_{E}, U\right) \in\{0,1\}$. If the worker accepts the offer $\left(D_{E}=1\right)$, he pays damages $r$ to firm $I$ and then starts to work for firm $E$ and receives wage $w_{E}$. If the worker rejects the offer $\left(D_{E}=0\right)$, he works for firm $I$ and gets wage $w_{I}$ while firm $E$ receives a reservation payoff of zero. We assume that renegotiation of the initial contract is not possible and that the worker accepts an offer when indifferent. Depending on the worker's acceptance decisions, $D_{I}$ and $D_{E}$, payoffs and social welfare are summarized in Table 1:

\begin{tabular}{|c|c|c|c|c|}
\hline & Firm $I$ & Firm $E$ & Worker & Social Welfare \\
\hline$D_{I}=0$ & 0 & 0 & $U$ & $U$ \\
\hline$D_{I}=1, D_{E}=0$ & $\beta-w_{I}$ & 0 & $w_{I}$ & $\beta$ \\
\hline$D_{I}=1, D_{E}=1$ & $r$ & $\beta-w_{E}$ & $b_{E}+w_{E}-r$ & $\beta+b_{E}$ \\
\hline
\end{tabular}

Table 1: Payoffs

Denoting the efficient acceptance decisions of the worker by $D_{k}^{F}$ for $k=I, E$, he should choose to accept firm I's offer whenever the expected surplus from doing so is higher than his outside option $U$, i.e. $D_{I}^{F}=1 \Leftrightarrow \beta+\int_{-a}^{a} f\left(b_{E}\right) d b_{E} \geq U \Leftrightarrow \beta \geq U$. It is assumed throughout that $\beta>\bar{U}$ so that it is never efficient that the worker pursues his outside option. Moreover the worker should work for firm $E$ whenever $b_{E}$ is non-negative, i.e. $D_{E}^{F}=1 \Leftrightarrow b_{E} \geq 0$.

The time structure of the basic game can be summarized as follows (see also figure 1): At date 1 , the initial contract $\Omega=\left(w_{I}, r\right)$ is offered. At date 2 , the worker decides whether or not to accept the offer. If $D_{I}=1$, then at date 3 , the worker learns $b_{E}$. At date 4, firm $E$ offers $w_{E}$ which, at date 5, the worker again either accepts or rejects. Afterwards, the worker works either for firm $I$ or for firm $E$. 


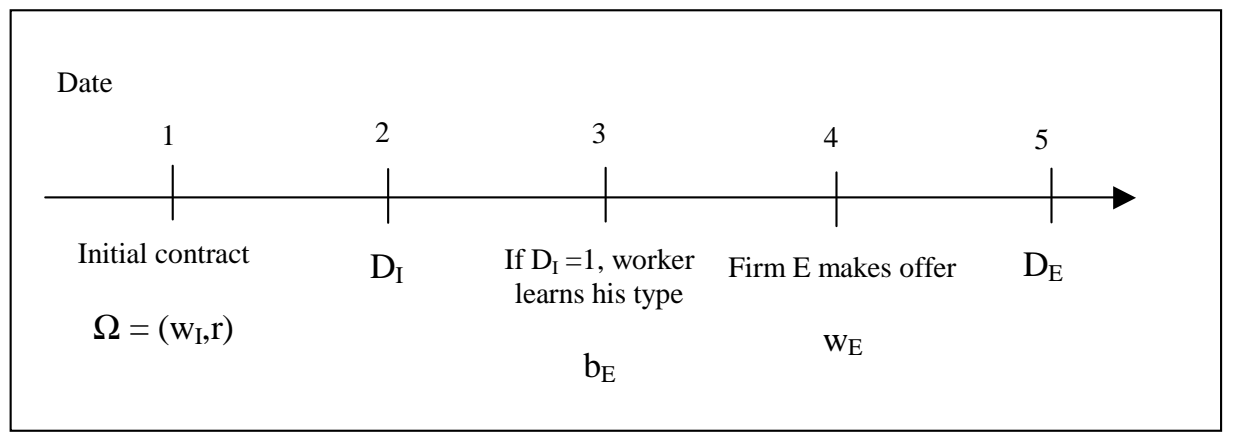

Figure 1: Sequence of Events

Denote by $q$ and $B$, respectively the probability that the worker accepts the offer by firm $E$ and the expected private benefit conditional on having accepted firm $E$ 's offer, i.e. $q \equiv \operatorname{Pr}\left(D_{E}=1\right)$ and $B \equiv E V\left(b_{E} / D_{E}=1\right)$, where $E V$ denotes "expected value". For the case where $D_{I}=1$, expected payoffs for firm $I$, firm $E$ and the worker, respectively, are:

$$
\begin{aligned}
\pi_{I} & =(1-q) \cdot\left(\beta-w_{I}\right)+q \cdot r \\
\pi_{E} & =q \cdot\left(\beta-w_{E}\right), \\
\pi_{W} & =(1-q) \cdot w_{I}+q \cdot\left(w_{E}+B-r\right),
\end{aligned}
$$

For the worker, for instance, with probability $(1-q)$ there is no transfer in which case he works for firm $I$ and gets the initial wage $w_{I}$, while with probability $q$ he works for firm $E$ and gets wage $w_{E}$ plus expected private benefit $B$, and has to pay $r$ to firm $I$. The payoffs for firms $I$ and $E$ can be interpreted analogously. Finally, expected social welfare in case that $D_{I}=1$ is simply given by adding up all payoffs, i.e.

$$
S W=\beta+q \cdot B
$$

\section{No Regulation of Damage Clauses}

In this section we analyze the case in which there is no legal restriction on the damage clause $r$, i.e. any $r \in \Re$ is assumed to be enforceable in court. For further reference, it is useful to define $R$ as the sum of the wage in firm $I$ and the liquidated damage clause: $R \equiv w_{I}+r$. We will refer to $R$ as the worker's "total switching cost" when leaving firm 
$I$ consisting of his opportunity costs $w_{I}$ and the damage clause $r$.

Date 5 Solving the game using backward induction, at date 5 the worker will accept firm $E$ 's offer, whenever his net benefit from doing so is non-negative, i.e. $D_{E}=1$ iff $b_{E}+w_{E}-r \geq w_{I} \Leftrightarrow b_{E}+w_{E} \geq R$. The borderline type which is just indifferent between accepting and rejecting is then implicitly defined by

$$
\widetilde{b}_{E}-R+w_{E}=0
$$

Given $\widetilde{b}_{E}$, the probability of a transfer is

$$
q=1-F\left(R-w_{E}\right)
$$

Date 4 For date 4, the wage offered by firm $E$ solves the following maximization problem

$$
\max _{w_{\mathrm{E}}}\left(1-F\left(R-w_{E}\right)\right) \cdot\left(\beta-w_{E}\right)
$$

Assuming an interior solution, the optimal value $w_{E}^{*}(R)$ satisfies the following first order condition:

$$
-1+F\left(R-w_{E}^{*}\right)+f\left(R-w_{E}^{*}\right)\left(\beta-w_{E}^{*}\right)=0 .
$$

The optimal wage offered by firm $E$ trades off the higher probability of acceptance when choosing a high $w_{E}$ vs. the direct beneficial effect of a lower wage. Also denoting other equilibrium variables with a "*", we have the following result for the continuation game at date 4 :

Lemma 1 i) For the continuation game at date 4, we have

$$
\widetilde{b}_{E}^{*}(R)=R-w_{E}^{*}(R), q^{*}(R)=1-F\left(R-w_{E}^{*}(R)\right), \text { and } B^{*}(R)=\frac{\int_{\widetilde{b}_{\mathrm{E}}^{*}(R)}^{a} b \cdot f(b) d b}{\int_{\widetilde{b}_{\mathrm{E}}^{*}(R)}^{a} f(b) d b} \text {. }
$$


ii) For the comparative statics with respect to $R$, we have $0<\frac{d w_{\mathrm{E}}^{*}}{d R}<1$, $\frac{\widetilde{d b}_{\mathrm{E}}^{*}}{d R}>0, \frac{d q^{*}}{d R}<0$ and $\frac{d B^{*}}{d R}>0$.

Proof. See Appendix A.

A higher level of $R$ induces firm $E$ to offer a higher wage, the borderline type which agrees to a transfer is higher and therefore, the probability of a transfer is lower and the expected private benefit, given that the offer has been accepted is higher.

Dates 3 and 2 At date 3, nature draws $b_{E}$, so the next stage in which one of the parties chooses an action is at date 2, where the worker decides whether or not to accept firm I's offer. Clearly, taking into account the continuation of the game, the worker will do so only if his expected payoff from doing so is (weakly) higher than his outside option, i.e. $D_{I}^{*}=1$ iff

$$
\begin{aligned}
\left(1-q^{*}(R)\right) \cdot w_{I}+q^{*}(R) \cdot\left[w_{E}^{*}(R)+B^{*}(R)-r\right] & = \\
\left.w_{I}+q^{*}(R)\right) \cdot\left[w_{E}^{*}(R)+B^{*}(R)-R\right] & \geq U
\end{aligned}
$$

Date 1 At date 1, firm I's payoff is given by

$$
\pi_{I}=\left\{\begin{array}{ll}
\left(1-q^{*}(R)\right) \cdot\left(\beta-w_{I}\right)+q^{*}(R) \cdot r & \text { if } D_{I}=1 \\
0 & \text { if } D_{I}=0
\end{array} .\right.
$$

The following lemma proves useful for the further analysis:

Lemma 2 For any $R \equiv w_{I}+r$ given and $w_{I}>0$, firm I can always be made strictly better off by increasing $r$ and decreasing $w_{I}$ by the same amount, thereby keeping $R$ constant.

Proof. Simply add and subtract $q^{*}(R) \cdot r$ so that $\pi_{I}=\left(1-q^{*}(R)\right) \cdot\left(\beta-w_{I}\right)+q^{*}(R) \cdot r$ can also be written as

$$
\pi_{I}=\left(1-q^{*}(R)\right) \cdot \beta+q^{*}(R) \cdot R-w_{I}
$$

which is decreasing in $w_{I}$. 
The lemma implies that, for $R$ given, firm $I$ prefers to offer a wage rate $w_{I}$ as low as possible to the worker. Although $w_{I}$ and $r$ are prefect substitutes vis a vis firm $E$, firm $I$ prefers to obtain a higher damage payment $r$ rather than paying a higher wage $w_{I}$. Clearly, there is a limit in lowering $w_{I}$ due to the non-negativity constraint for $w_{I}$.

Using Lemma 2 firm $I$ 's maximization problem for the case $D_{I}=1$ can be stated as

$$
\max _{w_{1}, R} \pi_{I}=\left(1-q^{*}(R)\right) \cdot \beta+q^{*}(R) \cdot R-w_{I}
$$

subject to the worker's participation constraint and the non-negativity constraint for $w_{I}$ :

$$
\begin{aligned}
\left.w_{I}+q^{*}(R)\right) \cdot\left[w_{E}^{*}(R)+B^{*}(R)-R\right] & \geq U \\
w_{I} & \geq 0 .
\end{aligned}
$$

where the respective damage clause is then just the residual, i.e. $r=R-w_{I}$.

Before analyzing the contract offered by firm $I$ in more detail, we will for later purpose first derive two benchmark results concerning the switching cost $R$. It is assumed that these two solutions are interior and therefore implicitly given by the respective first order condition.

Benchmark I: First Best First we determine $R^{F}$, the level of $R$ which maximizes expected social welfare, i.e.

$$
R^{F} \in \arg \max S W(R)=\beta+q^{*}(R) \cdot B^{*}(R)
$$

where $R^{F}$ solves the following first order condition:

$$
q^{* \prime}\left(R^{F}\right) \cdot B^{*}\left(R^{F}\right)+q^{*}\left(R^{F}\right) \cdot B^{* \prime}\left(R^{F}\right)=0
$$

The first term is the marginal loss from a lower level of $q$ while the second term is the gain due to a higher expected private benefit $b_{E}$ if the transfer is realized (see Lemma 1 part ii)). Note that $q^{*}\left(R^{F}\right)$ will ensure that the worker will choose to accept firm $E$ 's offer exactly when this is socially desirable, i.e. whenever $b_{E} \geq 0$, i.e. it induces $\widetilde{b}_{E}=0$ 
and thus $R^{F}=w_{E}$ holds. ${ }^{10}$

Benchmark II: Maximization of Joint Payoff As a second benchmark case, we determine the level of switching costs $R^{J}$ which maximizes the joint payoff of firm $I$ and the worker, i.e.

$$
\begin{aligned}
R^{J} & \in \arg \max J(R) \equiv \pi_{I}+\pi_{W} \\
& =\left(1-q^{*}(R)\right) \cdot \beta+q^{*}(R) \cdot\left(w_{E}^{*}(R)+B^{*}(R)\right) \\
& =S W(R)-q^{*}(R) \cdot\left(\beta-w_{E}^{*}(R)\right)
\end{aligned}
$$

so that the respective following first order condition is

$$
q^{* \prime}\left(R^{J}\right) \cdot B^{*}\left(R^{J}\right)+q^{*}\left(R^{J}\right) \cdot B^{* \prime}\left(R^{J}\right)-\left[q^{* \prime}\left(R^{J}\right)\left(\beta-w_{E}^{*}\right)-q^{*}\left(R^{J}\right)\left(\frac{d w_{E}^{*}}{d R}\right)\right]=0 .
$$

This immediately leads to the following result:

Proposition 1 The maximization of the joint surplus of the worker and firm I induces excessive switching costs for the worker, i.e. $R^{J}>R^{F}$ holds. This prevents inefficiently many transfers, i.e. $q^{*}\left(R^{J}\right)<q^{*}\left(R^{F}\right)$.

\section{Proof. See Appendix B.}

Intuitively, $R^{J}$ will not ensure that the worker will always be transferred whenever it is efficient. Rather, it leads to an inefficiency in a sense that the probability of a transfer is too small. The reason for this inefficiency is the extraction of rents from firm $E$ which can be shared ex ante between the worker and firm $I$. To see this note that it follows from Lemma 1 that firm $E$ 's equilibrium profit is strictly decreasing in $R$ :

$$
\left(1-F\left(\widetilde{b}_{E}^{*}(R)\right)\right) \cdot\left(-\frac{d w_{E}^{*}(R)}{d R}\right)-f\left(\widetilde{b}_{E}^{*}(R)\right) \cdot \frac{\widetilde{d b}_{E}^{*}}{d R} \cdot\left(\beta-w_{E}^{*}(R)\right)<0
$$

\footnotetext{
${ }^{10}$ Checking that the first order condition (15) is satisfied at $\widetilde{b}_{\mathrm{E}}=0$ yields
}

$$
\frac{-f(0) \cdot \int_{0}^{a} b \cdot f(b) d b}{1-F(0)}+(1-F(0)) \frac{-f(0) \cdot 0 \cdot F(0)+f(0) \cdot \int_{0}^{a} b \cdot f(b) d b}{(1-F(0))^{2}}=0 .
$$


It follows that there is the following trade-off when negotiating the initial contract: On the one hand leads a high level of $R$ to higher rent extraction from firm $E$, whereby both, $w_{I}$ and $r$ have the function of increasing the "threat point" of the worker and firm $I$ vis-a-vis firm $E$. Moreover, they are perfect substitutes in performing this function. On the other hand, this also prevents efficient transfers for some realizations of $b_{E}$. These two effects are balanced at the margin by $R^{J}$. Note that this result is qualitatively robust against changes in how the surplus is shared ex ante between the worker and firm $I:{ }^{11}$

We can now the analyze the initial contract offered by firm $I$ at date 1 in more detail: Since firm $I$ has all the bargaining power at the initial contracting stage, it prefers to concede a stake of the joint surplus as small as possible to the worker. This is true when the outside option of the worker is binding. However, keeping the worker at his outside option may not be feasible for a given level of $U$, since it would require some $w_{I}<0$ therefore violating constraint (13). ${ }^{12}$ From Lemma 2 it follows that $w_{I}=0$ will be chosen in this case. On the other hand when the worker's participation constraint (12) is binding at some $w_{I}>0$, thereby not violating constraint (13), then firm $I$ 's will simply maximize expected joint payoff minus a constant.

For the remainder of the analysis, it is assumed that $b_{E}$ is uniformly distributed according to the distribution function $F\left(b_{E}\right)=\frac{a+b_{E}}{2 a}$. This allows to derive an explicit solution for the scenarios with and without regulation of damage clauses and makes the comparison of these scenarios more tractable. With $F\left(b_{E}\right)=\frac{a+b_{E}}{2 a}$, the equilibrium outcome at date 4 is $w_{E}^{*}(R)=\frac{R+\beta-a}{2 a}, \widetilde{b}_{E}^{*}(R)=\frac{R-\beta+a}{2}, q^{*}(R)=\frac{a-R+\beta}{4 a}$ and $B^{*}(R)=$ $\frac{3 a+R-\beta}{4 a}$. Furthermore, we get $R^{F}=\beta-a$, and $R^{J}=\beta+\frac{a(2 a-1)}{2 a+1}>R^{F}$. Furthermore, the following additional assumption is sufficient to ensure that all relevant levels of $R$ are positive and that all equilibrium values at date 4 are interior:

Assumption $1 \beta>\frac{3}{2} a$ and $a \geq 1$.

We then have the following result:

\footnotetext{
${ }^{11}$ It can be shown that even if the player could make a take-it-or-leave-it offer to firm $I$, he would choose a contract which prevents efficient transfers for some realizations of $b_{\mathrm{E}}$.

${ }^{12}$ Recall, that the worker also obtains utility in form of the private benefit $b_{\mathrm{E}}$ in case of a transfer.
} 
Proposition 2 When $b_{E}$ is uniformly distributed according to $F\left(b_{E}\right)=\frac{a+b_{E}}{2 a}$, then the optimal initial contract $\Omega^{*}=\left(w_{I}^{*}, r^{*}\right)$ offered by firm I stipulates:

i) A wage $w_{I}^{*}(U)>0$ and a damage clause $r^{*}(U)=R^{J}-w_{I}^{*}$

for $\max \left(0, \frac{4 a+1-4 a^{2}}{4(2 a+1)^{2}}\right) \leq U \leq \bar{U}$.

ii) $A$ wage $w_{I}^{*}(U) \equiv 0$ and a damage clause $r^{*}(U)=R^{*}(U) \in\left(R^{J}, \beta+\frac{1}{2} a\right)$ for $\max \left(0, \frac{7}{64}-\right.$ $\left.\frac{3}{32} a\right) \leq U<\max \left(0, \frac{4 a+1-4 a^{2}}{4(2 a+1)^{2}}\right)$.

iii) $A$ wage $w_{I}^{*}(U) \equiv 0$ and a damage clause $r^{*}(U) \equiv \beta+\frac{1}{2} a$ for $0 \leq U<\max \left(0, \frac{7}{64}-\frac{3}{32} a\right)$.

iv) The worker chooses to accept the contract in either case, i.e. $D_{I}^{*}\left(\Omega^{*}, U\right) \equiv 1 \forall U$.

\section{Proof. See Appendix C.}

The intuition behind this result (also illustrated in figure 2) can be explained as follows: When the reservation utility of the worker is high enough, constraint (12) is binding at a positive wage so that firm $I$ maximizes $J S(R)$ minus a constant thus implements $R^{J}$ which explains part i) of the Proposition (see the left panel in figure 2). As for part ii), when $U$ decreases, then the wage $w_{I}$ which satisfies the participation constraint of the worker with equality would be negative and therefore violates constraint (13). In this case, the worker gets $w_{I}^{*}=0$ and would earn a rent if firm $I$ would continue to choose $R^{J}$. In order to avoid conceding a rent to the worker, the damage clause $r^{*}$ offered by firm $I$ leads to $R^{*}>R^{J}$ which even more distorts the equilibrium level of switching costs from its first best level $R^{F}$. In part ii), firm $I$ continues to keep the worker at his reservation payoff at the expense of an even higher level of $R$. How much $R^{*}$ differs from $R^{J}$ depends on $U$ (see the panel in the middle of figure 2). As for part iii), if $U$ is sufficiently low, then firm $I$ prefers to concede a rent to the worker in order not to induce too high a level of switching costs (see the right panel in figure 2). Thus, additional from the rent seeking motive vis a vis firm $E$, there is an additional effect related to the rent for the worker, which both lead to an excessive damage clause.

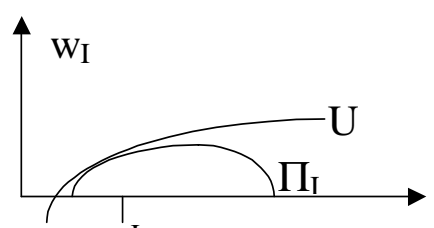

$\mathrm{R}^{\mathrm{J}}$
$\mathrm{R}$

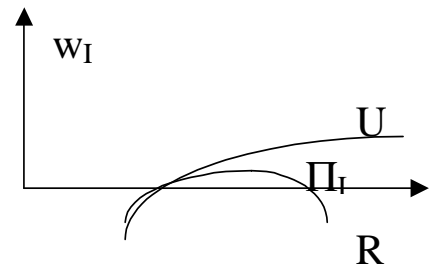

$\mathrm{R}$

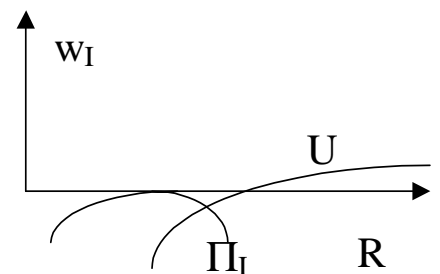

$\mathrm{R}$

Figure 2: Illustration of the optimal contract 


\section{Regulation of damage clauses}

In the last section we saw that freedom of contract leads to a distortion of the damage clause from its efficient level in order to reduce rents of firm $E$ and, depending on $U$, also of the worker. Consequently in this section, we explore whether a regulator can improve upon the outcome under freedom of contract. In particular, we enquire how an upper bound on the enforceable damage clause might improve matters. From a practical point of view, an upper bound $\bar{r}$ means that all $r>\bar{r}$ will not be enforced by the court and are therefore not contractible. Moreover, any $\bar{r}<0$ would have the unrealistic implication that it were impossible for parties to write a contract without specifying a damage clause at all (which is equivalent to stipulating $r=0$ ). Therefore, only $\bar{r} \geq 0$ are assumed to be feasible. The timing of the game is the same as in the unregulated case except that at date 0 , the regulator sets $\bar{r}$. The continuation of the game for date 4 as established by Lemma 1 as well as the nature's move at date 3 and the acceptance decision of the worker at date 2 remain unchanged. Therefore in a first step, we have to determine the contract offered by firm $I$ at date 1 for $U$ and $\bar{r}$ given, and then the regulator's optimal choice of $\bar{r}$ for date 0 .

Firm I's choice at date 1 At date 1 , for the case $D_{I}=1$, the firm $I$ 's maximization problem is given by:

$$
\max _{w_{1}, R} \pi_{I}=\left(1-q^{*}(R)\right) \cdot \beta+q^{*}(R) \cdot R-w_{I}
$$

subject to the participation constraints of the worker, the non-negativity constraint of the worker and the constraint that the damage clause must not exceed $\bar{r}$ :

$$
\begin{aligned}
\left.w_{I}+q^{*}(R)\right) \cdot\left[w_{E}^{*}(R)+B^{*}(R)-R\right] & \geq U \\
w_{I} & \geq 0 \\
R-w_{I} & \leq \bar{r}
\end{aligned}
$$

Clearly, the problem is identical to the scenario without regulation except for the additional constraint $R-w_{I}=r \leq \bar{r}$. The solution to the problem is more complex, since we 
have to find the solution for all $U$ and $\bar{r}$, i.e. the relevant parameter space is $[0, \bar{U}] \times \Re_{0}^{+}$. When determining the initial contract optimally offered by firm $I$ at date 1 , again two cases can be distinguished, one where constraint (13) is binding in the optimal contract and one where it is not. We continue to perform the analysis for the case in which $b_{E}$ is uniformly distributed according to the distribution function $F\left(b_{E}\right)=\frac{a+b_{E}}{2 a}$.

When constraint (21) is not binding in the optimal initial contract, then the contract offered by firm $I$ at date 1 has the following properties:

Proposition 3 When $b_{E}$ is uniformly distributed according to $F\left(b_{E}\right)=\frac{a+b_{E}}{2 a}$, and constraint (21) is not binding, then apart from $w_{I}^{*}>0$, the initial contract stipulates:

i) A damage clause $r^{*}(U, \bar{r}) \equiv \bar{r}$ such that $R^{*}(U, \bar{r}) \equiv \beta-\frac{3}{2} a$ for $U \leq \beta-\frac{43}{32} a+\frac{15}{64}-\bar{r}$ and $\bar{r}<\beta-\frac{3}{2} a$.

ii) A damage clause $r^{*}(U, \bar{r})=\bar{r}$ such that $R^{*}(U, \bar{r}) \in\left[\beta-\frac{3}{2} a, R^{J}\right)$, for $\beta-\frac{43}{32} a+\frac{15}{64}-\bar{r}<$ $U<\frac{16 a(\beta(a+1)+a(a-\bar{r})-\bar{r})+4\left(\beta-\bar{r}-a^{2}\right)+1}{4(2 a+1)^{2}}$ when $\beta-\frac{3}{2} a<\bar{r}$ and for $\frac{2 \bar{r} \beta-\beta^{2}-\bar{r}^{2}-a\left(2\left(a^{2}+\bar{r}-\bar{r}^{2}-\beta+2 \bar{r} \beta-\beta^{2}\right)-3 a\right)}{16 a^{2}}<$ $U<\frac{16 a(\beta(a+1)+a(a-\bar{r})-\bar{r})+4\left(\beta-\bar{r}-a^{2}\right)+1}{4(2 a+1)^{2}}$ when $\bar{r} \geq \beta-\frac{3}{2} a$.

iii) A damage clause $r^{*}<\bar{r}$ such that $R^{*}(U, \bar{r}) \equiv R^{J}$

for $\frac{16 a(\beta(a+1)+a(a-\bar{r})-\bar{r})+4\left(\beta-\bar{r}-a^{2}\right)+1}{4(2 a+1)^{2}} \leq U \leq \bar{U}$ and $U>\max \left(0, \frac{4 a+1-4 a^{2}}{4(2 a+1)^{2}}\right)$.

iv) The worker chooses to accept the contract in either case, i.e. $D_{I}^{*}\left(\Omega^{*}, U\right) \equiv 1 \forall U$.

Proof. See Appendix D.

The intuition for this result, also illustrated in figure 3, is as follows: As seen in Proposition 2, absent any restriction on $r$, whenever $w_{I}^{*}>0$, firm $I$ keeps the worker at his reservation payoff $U$, in which case the optimal choice would be $R^{J}$. However, when additionally $r \leq \bar{r}$ has to hold, this may no longer be optimal: When $\bar{r}$ is sufficiently low, then firm $I$ is willing to pay a positive wage $w_{I}$ in order to distort $R^{*}$ not too much from $R^{J}$ (part i) of the Proposition and region $A 1$ in the figure), even leaving a rent to the worker, while still choosing the maximum damage clause $\bar{r}$. For intermediate values of $\bar{r}$, implementing $R^{J}$ would require too high a wage $w_{I}$ so that firm $I$ optimally chooses some $R^{*}<R^{J}$ (part ii) and region $A 2$ in the figure). In this case, the worker is kept at his reservation utility and no longer earns a rent. As for part iii), when $\bar{r}$ is sufficiently high, firm $I$ implements $R^{J}$ with the minimum wage necessary to satisfy the worker's participation constraint (this corresponds to region $A 3$ in the figure). 


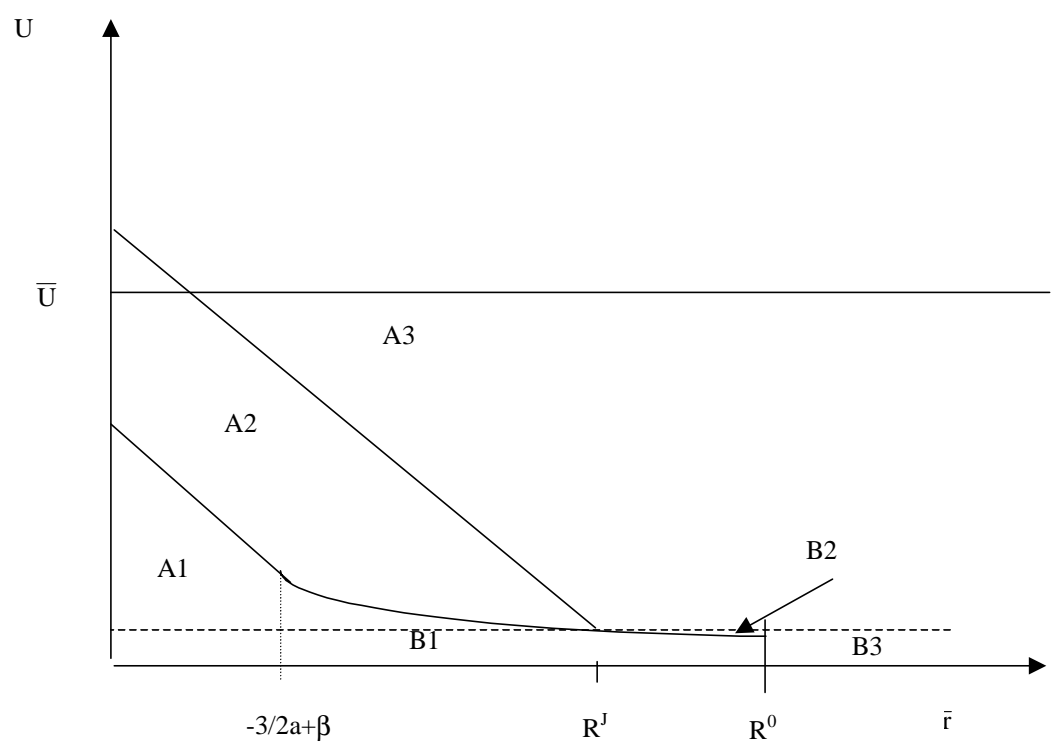

Figure 3: Relevant Parameter Regions for $(U, \bar{r})$

When constraint (21) is binding in the optimal initial contract, additional to $w_{I}^{*}=0$ the contract offered by firm $I$ at date 1 is as follows:

Proposition 4 When $b_{E}$ is uniformly distributed according to $F\left(b_{E}\right)=\frac{a+b_{E}}{2 a}$, then additional to $w_{I}^{*}=0$, the initial contract stipulates:

i) A damage clause $r^{*}(U, \bar{r})=R^{*}=\bar{r}$

for $U \leq \frac{2 \bar{r} \beta-\beta^{2}-r^{2}-a\left(2\left(a^{2}+\bar{r}-\bar{r}^{2}-\beta+2 \bar{r} \beta-\beta^{2}\right)-3 a\right)}{16 a^{2}}$ and $\bar{r} \in\left[\beta-\frac{3}{2} a, \beta+\frac{1}{2} a\right)$.

ii) A damage clause $r^{*}(U, \bar{r})=R^{*} \in\left[R^{J}, \beta+\frac{1}{2} a\right) \leq \bar{r}$

for $U>\frac{2 \bar{r} \beta-\beta^{2}-\bar{r}^{2}-a\left(2\left(a^{2}+\bar{r}-\bar{r}^{2}-\beta+2 \bar{r} \beta-\beta^{2}\right)-3 a\right)}{16 a^{2}}$ and $\bar{r} \in\left[R^{J}, \beta+\frac{1}{2} a\right)$.

iii) A damage clause $r^{*}(U, \bar{r})=R^{*} \equiv \beta+\frac{1}{2} a \leq \bar{r}$

for $U \leq \frac{2 \bar{r} \beta-\beta^{2}-\bar{r}^{2}-a\left(2\left(a^{2}+\bar{r}-r^{2}-\beta+2 \bar{r} \beta-\beta^{2}\right)-3 a\right)}{16 a^{2}}$ and $\bar{r} \geq \beta+\frac{1}{2} a$.

iv) The worker chooses to accept the contract in either case, i.e. $D_{I}^{*}\left(\Omega^{*}, U\right) \equiv 1 \forall U$.

Proof. See Appendix E.

Intuitively, firm $I$ chooses the maximum possible $r$ as long as this is not higher than what it would choose in the unconstrained case. For part i), as long as $\bar{r}$ is low the worker cannot be kept at his reservation payoff and earns a rent, while by choosing $r=\bar{r}$, firm $I$ is doing "the best" it can do given that $w_{I}=0$ (see region $B 1$ in figure 3 ). As $\bar{r}$ increases and for sufficiently low levels of $U$, the worker can be kept at his reservation payoff without violating constraint (13) (regions $B 2$ and $B 3$ in figure 3) 
The Regulator's optimal choice of $\bar{r}$ at date $\mathbf{0}$ Using the previous results, we can now determine the regulator's optimal choice of $\bar{r}$ at date 0 depending on $U$. Since we have seen that an inefficiently high level of $R$ is implemented for all $U$ in the unregulated case, it can never be optimal for the regulator to set $\bar{r}>\beta+\frac{1}{2} a$, because it can always replicate the outcome of the unregulated case by simply setting $\bar{r}=\beta+\frac{1}{2} a$ while the expected social surplus is strictly decreasing in $R$ for $R>R^{F}$. For the regulator's optimal choice, the following result holds:

Proposition 5 When $b_{E}$ is uniformly distributed according to $F\left(b_{E}\right)=\frac{a+b_{E}}{2 a}$, then, at date 0 , the regulator optimally chooses

i) $\bar{r}^{*}(U) \equiv R^{F}$ for $0 \leq U \leq \frac{1}{4}$

ii) $\bar{r}^{*}(U)=R^{F}+\frac{1}{4}-U$, thereby still implementing $R^{F}$, for $\frac{1}{4}<U \leq R^{F}+\frac{1}{4}$

iii) $\bar{r}^{*}(U) \equiv 0$ thereby implementing some $R \in\left(R^{F}, R^{J}\right)$, for $R^{F}+\frac{1}{4}<U \leq \bar{U}$.

\section{Proof. See Appendix F.}

Intuitively, as long as $U$ is sufficiently low, the regulator can simply implement $R^{F}$ by choosing $\bar{r}=R^{F}$ since $w_{I}^{*}=0$ holds in the continuation game (i.e. as long as we are in region $B 1$ in figure 3 ). When $U$ increases and $w_{I}^{*}>0$ holds in the continuation game (i.e. as we move to region $A 2$ in figure 3 ), the regulator can still implement $R^{F}$ by choosing $\bar{r}$ appropriately. However, there is limit due to $\bar{r} \geq 0$. Thus for all $U>R^{F}+\frac{1}{4}, R^{F}$ can no longer be reached and the best choice of the regulator is $\bar{r}^{*}=0$ so that $R>R^{F}$ results. Thus, when $U$ is sufficiently large, the best choice for the regulator is to impose a ban of damage clauses.

\section{Comparison of both scenarios}

In this section we compare the results from the regulated and the unregulated case. Using the result from Proposition 2, we know that in equilibrium, the minimum level of switching costs is $R^{J}$. From Proposition 1 we know that expected social welfare is strictly decreasing in $R$ in this range. Therefore the maximum level of expected social welfare attainable in the unregulated case is $S W\left(R^{J}\right)$. However, this is less than what can be 
achieved in the scenario with regulation, no matter in which region as it was shown that either $R^{F}$ or some $R^{*}<R^{J}$ is implemented and thus the minimum level of expected social welfare is strictly higher than $S W\left(R^{J}\right)$. This is summarized in the following proposition:

Proposition 6 For all $U \in[0, \bar{U}]$, the equilibrium switching costs are strictly higher in the unregulated case. As a result, expected social welfare is strictly higher in the regulated case.

Thus, this proposition provides a strong case for restricting the freedom of contract: For any $U$ does an upper bound on the enforceable damage clauses increase expected social welfare. ${ }^{13}$

\section{Conclusion}

The previous analysis provides a strong case why restricting the freedom of contract by putting an upper bound on contractually stipulated damage clauses is welfare improving: Due to a rent seeking motive, the initial parties to a contract have an incentive to write an excessive damage clause in the initial contract. This clause prevents efficient transfers of the worker for some realization of $b_{E}$. Moreover, when the non-negativity constraint for the wage rate is binding, firm $I$ has an incentive to increase $R$ even more to avoid/reduce the rent of the worker. The regulator can counterbalance these incentives by setting $\bar{r}$ appropriately.

Since many assumptions underlie the analysis, some of them shall now be discussed in more detail:

Non-negativity constraint for $w_{I}$ Concerning the supports for $w_{I}$ and $r$, the alternative interpretation of $w_{I} \geq 0$ as a wealth constraint appears somewhat critical, since this would imply that although the worker cannot afford to pay a wage $w_{I}<0$, he is be able to pay any damage payment $r$. Note however, that he has to pay $r$ only if he works for firm $E$, in which he gets $w_{E} \geq 0$ in return. Of course, since he also receives the

\footnotetext{
${ }^{13}$ As outlined in the introduction to this chapter, there are two reasons why this comparison is not ambigous as in Chung (1992, table 1): One is that the "PD" rule is endogenously derived in the present model, the other is that investment incentives are not considered.
} 
private benefit $b_{E}$, it is not assured that $w_{E}>r$ holds in which case he might still need external funds to carry out the transfer. However at least, this suggests that a possible wealth constraint of the worker seems less strict with respect to $r$ than with respect to $w_{I}$. Therefore, we believe that assuming this extreme case to be justified. Alternatively, one could assume that firm $E$ has to pay $r$ in which case the problem would disappear and the results would be qualitatively unchanged. However, this seems to contradict reality. In fact, one of the very few segments of the labor market in which damages are to be paid by the new employer is the market for professional athletes. Finally, the case $w_{I} \in \Re$ is not an interesting one, because then the worker's participation constraint can always be made binding by a sufficiently low $w_{I}$ which implies that firm $I$ 's offer will maximizes $J S(R)$ minus a constant so that it will always offer $R^{J}$.

Bargaining between the worker and firm $I$ Note that contrary to many applications in the literature, the size of the expected surplus to be shared ex ante among the worker and firm $I$ is not fixed in our model but endogenously determined by the nature of the initial contract $\Omega=\left(w_{I}, r\right)$. Concerning the modeling assumption how the surplus is split in the initial contract, it is clear that one could alternatively assume that the worker and firm $I$ engage in Nash bargaining by maximizing the generalized NashProduct $\pi_{I}^{\alpha} \pi_{W}^{1-\alpha}$ where $\alpha \in(0,1)$ denotes the bargaining power of firm $I .{ }^{14}$. However, this approach would make the model rather intractable. Moreover, any split of the joint surplus which can be achieved when using the Nash bargaining approach by variation of $\alpha$, can also be achieved by varying $U$ accordingly in the present model. Therefore, it seems a reasonable approach to use the outside option of the worker as a proxy for his bargaining power while allowing firm $I$ to make a take-it-or-leave-it offer.

Bargaining between the worker and firm $E$ The assumption that the new firm is able to make a take-it-or-leave-it offer to the worker is strong but not crucial in order to derive the results qualitatively. What is important is that firm $E$ reaps a positive share of the surplus. Otherwise, we would be back in the case in which there would be

\footnotetext{
${ }^{14}$ For an application in the context of lender liability, see e.g. Balkenborg (2001).
} 
no externalities from contracting so that no rent seeking motive vis a vis firm $E$ arises. ${ }^{15}$ In this case, firm $I$ and the worker would have the right incentives in case the worker's outside option is binding, while there would still be a rent reduction incentive for firm $I$ when the non-negativity constraint $w_{I} \geq 0$ is binding.

No Signaling or Screening Devices That workers are not able to signal their private information seems a reasonable assumption for some segments of the labor market while it is not for others where it might well be the case that signaling is either not possible or excessively costly. Since firm $E$ is assumed to have only the possibility of offering a wage rate $w_{E}$ to the worker, it is clear that there is no way in inducing different types to act differently since there would have to be at least a second choice variable which could be used in order to ensure incentive compatibility. Clearly, one might want to enrich the model in that direction.

Another interesting extension would be to include an investment choice of one of the initial parties. For example, in case that the productivity of the worker in firms $I$ and $E$ is a function of firm $I$ 's (general) investment, reducing the initial parties' ability to stipulate liquidated damages would lead to lower investment incentives, which would make the results concerning the desirability of these kinds of restrictions somewhat ambiguous.

\section{A ppendix}

\section{A Proof of Lemma 1}

Part i): Follows immediately from substituting the equilibrium values in (5), (6) and the definition of $B$.

Part ii): From (8), applying the implicit function theorem we have

$$
\begin{aligned}
\frac{d w_{E}^{*}}{d R} & =-\frac{f\left(R-w_{E}^{*}\right)+f^{\prime}\left(R-w_{E}^{*}\right)\left(\beta-w_{E}^{*}\right)}{(-1) \cdot\left(2 f\left(R-w_{E}^{*}\right)+f^{\prime}\left(R-w_{E}^{*}\right)\left(\beta-w_{E}^{*}\right)\right)} \\
& =\frac{f\left(R-w_{E}^{*}\right)+f^{\prime}\left(R-w_{E}^{*}\right)\left(\beta-w_{E}^{*}\right)}{2 f\left(R-w_{E}^{*}\right)+f^{\prime}\left(R-w_{E}^{*}\right)\left(\beta-w_{E}^{*}\right)}
\end{aligned}
$$

\footnotetext{
${ }^{15}$ See the models by Shavell (1980), Rogerson (1984) or Chung (1992) (for $\alpha=0$ ) discussed in chapter ??.
} 
and thus $0<\frac{d w_{E}^{*}}{d R}<1$ since by Assumption, $f\left(R-w_{E}^{*}\right)>0$, and $f^{\prime}\left(R-w_{E}^{*}\right) \geq 0$. Moreover $\left(\beta-w_{E}^{*}\right)$ is must also be non-negative since otherwise, firm $E$ would obtain a negative payoff and thus prefer its reservation payoff of zero to making an offer to the worker. From this result, it follows that $\frac{d \widetilde{b}_{\mathrm{E}}^{*}}{d R}=1-\frac{d w_{\mathrm{E}}^{*}}{d R}>0$ and $\frac{d q^{*}}{d R}=-f\left(R-w_{E}^{*}\right)\left(1-\frac{d w_{E}^{*}}{d R}\right)<0$. For the comparative statics result for $B^{*}$ we have

$$
\begin{aligned}
\frac{d B^{*}}{d R}=\frac{\int_{\widetilde{b}_{\mathrm{E}}^{*}(R)}^{a} f(b) d b \cdot\left(-\widetilde{b}_{E}^{*} \cdot f\left(\widetilde{b}_{E}^{*}\right) \cdot \frac{\widetilde{d b}_{\mathrm{E}}^{*}}{d R}\right)-\int_{\widetilde{b}_{\mathrm{E}}^{*}(R)}^{a} b \cdot f(b) d b \cdot\left(-f\left(\widetilde{b}_{E}^{*}\right) \cdot \frac{\widetilde{d b}_{\mathrm{E}}^{*}}{d R}\right)}{\left(\int_{\widetilde{b}_{\mathrm{E}}^{*}(R)}^{a} f(b) d b\right)^{2}} \\
=\frac{\left(-f\left(\widetilde{b}_{E}^{*}\right) \cdot \frac{\widetilde{b}_{\mathrm{E}}^{*}}{d R}\right)\left(\widetilde{b}_{E}^{*} \cdot \int_{\widetilde{b}_{\mathrm{E}}^{*}(R)}^{a} f(b) d b-\int_{\widetilde{b}_{\mathrm{E}}^{*}(R)}^{a} b \cdot f(b) d b\right)}{\left(\int_{\widetilde{b}_{\mathrm{E}}^{*}(R)}^{a} f(b) d b\right)^{2}}>0 .
\end{aligned}
$$

Note that the second term in the numerator is negative, i.e.

$$
\widetilde{b}_{E}^{*}<\frac{\int_{\widetilde{b}_{\mathrm{E}}^{*}(R)}^{a} b \cdot f(b) d b}{\int_{\widetilde{b}_{\mathrm{E}}^{*}(R)}^{a} f(b) d b}=B
$$

holds, because the expected value cannot be smaller than the lower bound of the integral.

\section{B Proof of Proposition 1}

For the comparison of $R^{F}$ and $R^{J}$, it suffices to compare the first order conditions (15) and (17): Since the term $\left[q^{* \prime}\left(R^{J}\right)\left(\beta-w_{E}^{*}\right)+q^{*}\left(R^{J}\right)\left(-\frac{d w_{E}^{*}}{d R}\right)\right]$ in (17) (measuring the effect of an increase of $R$ on the expected profits of firm $E$ ) is negative, the marginal cost of increasing $R$ for the worker and firm $I$ is lower than the social marginal cost. Therefore, $R^{J}>R^{F}$ holds. 


\section{Proof of Proposition 2}

After simplifying, firm I's maximization can be re-written in the standard form for nonlinear programming:

$$
\begin{aligned}
& \max _{w_{1}, R}\left(1-\frac{a-R+\beta}{4 a}\right) \cdot \beta+\left(\frac{a-R+\beta}{4 a}\right) \cdot R-w_{I} \\
\text { s.t. }-U \geq & -w_{I}+\left(\frac{a-R+\beta}{16 a^{2}}\right)(a(2(R-\beta+a)-3)-R+\beta) \\
0 \geq & -w_{I}
\end{aligned}
$$

The Lagrangian $Z$ is then given by

$$
\begin{aligned}
Z=\left(1-\frac{a-R+\beta}{4 a}\right) & \cdot \beta+\left(\frac{a-R+\beta}{4 a}\right) \cdot R-w_{I} \\
& -y_{1}\left(-w_{I}+\left(\frac{a-R+\beta}{16 a^{2}}\right)(a(2(R-\beta+a)-3)-R+\beta)\right)+y_{2} w_{I}
\end{aligned}
$$

where $y_{1}$ and $y_{2}$ denote the respective multipliers. The objective function is quasi-concave in $R$ and $w_{I}$ and both constraints are quasi-convex in $R$ and $w_{I}$. Moreover, since neither the objective function is strictly concave in $R, w_{I}$ nor are all constraints strictly convex in $R, w_{I}$, to apply the result by Arrow and Enthoven (1961), two further conditions must be met. ${ }^{16}$ Then the result by Arrow and Enthoven (1961) states that the Kuhn-Tucker

\footnotetext{
${ }^{16}$ These conditions are that i) there must exist a point $\left(R^{0}, w_{1}^{0}\right)$ for which all constraints are satisfied as strict inequalities and ii), there must not exist a point $\left(R^{1}, w_{1}^{1}\right)$ at which the partial derivatives of all constraints with resepct to $R$, and $w_{1}$ are zero. Both conditions are met in the present context.
} 
conditions are sufficient for a maximum. The respective Kuhn-Tucker conditions are

$$
\begin{aligned}
\frac{\partial Z}{\partial R} & =0 \\
\frac{\partial Z}{\partial w_{I}} & =0 \\
-U & \geq-w_{I}+\left(\frac{a-R+\beta}{16 a^{2}}\right)(a(2(R-\beta+a)-3)-R+\beta) \\
0 & \geq-w_{I} \\
y_{1}, y_{2} & \geq 0 \\
0 & =y_{1}\left[w_{I}-\left(\frac{a-R+\beta}{16 a^{2}}\right)(a(2(R-\beta+a)-3)-R+\beta)-U\right] \\
0 & =y_{2} w_{I}
\end{aligned}
$$

First, consider a solution with $w_{I}^{*}>0$, which implies $y_{2}=0$ (from $(29)$ ) and $y_{1}=1$. Then (23) yields $R^{*}=\beta+\frac{a(2 a-1)}{2 a+1}=R^{J}$ while (25) must be binding so that $w_{I}=$ $\frac{4(a(a+4 U(a+1)-1)+U)-1}{4(2 a+1)^{2}}$ which is positive for all $U>\frac{4 a+1-4 a^{2}}{4(2 a+1)^{2}}$ so that this is the solution to the problem for all $U>\max \left(0, \frac{4 a+1-4 a^{2}}{4(2 a+1)^{2}}\right)$. This explains part i) of the Proposition.

When $w_{I}^{*}=0$ then $y_{2} \geq 0$. Case 1: $y_{2}=0$ which implies $y_{1}=1$. Again (23) yields $R^{*}=\beta+\frac{a(2 a-1)}{2 a+1}=R^{J}$ while $(25)$ yields $w_{I}=\frac{4(a(a+4 U(a+1)-1)+U)-1}{4(2 a+1)^{2}}$ which is strictly increasing in $U$ and equal to zero for $U=\frac{4 a+1-4 a^{2}}{4(2 a+1)^{2}}$. Case 2: $y_{2}>0$. Again we have two sub-cases: Case 2a: $0<y_{2}<1$ and $y_{1}=1-y_{2}>0$. In this case, constraint (25) must also be binding so that we have a system with 3 equations $((23),(24)$ and $(25))$ and three endogenous variables $\left(R, y_{1}, y_{2}\right)$ which gives $R^{*}=\tau, y_{1}=2 a \frac{2 \beta+a-2 \tau}{\tau-2 \tau a+2 \beta a+a-\beta}$ and $y_{2}=\frac{\gamma+2 \tau a-2 \beta a+a-\beta-2 a^{2}}{\tau-2 \tau a+2 \beta a+a-\beta}$, where

$$
\tau(U)=\frac{1}{2(-1+2 a)}\left(2(a-\beta+2 \beta a)-4 \sqrt{a^{2}\left(4 U(2 a-1)+(a-1)^{2}\right)}\right) .
$$

We have $y_{1}, y_{1}>0$ for $U \in\left(\frac{7}{64}-\frac{3}{32} a, \frac{4 a+1-4 a^{2}}{4(2 a+1)^{2}}\right)$ which implies that $R^{*} \in\left(\beta+\frac{a(2 a-1)}{2 a+1}, \beta+\right.$ $\left.\frac{1}{2} a\right)=\left(R^{J}, \beta+\frac{1}{2} a\right)$. Note that we have $\tau(U)>0$ for $U \in\left(\frac{7}{64}-\frac{3}{32} a, \frac{4 a+1-4 a^{2}}{4(2 a+1)^{2}}\right)$ and that $\frac{4 a+1-4 a^{2}}{4(2 a+1)^{2}}>\frac{7}{64}-\frac{3}{32} a$ holds. Case $2 \mathrm{a}$ is therefore part of the solution whenever $\frac{4 a+1-4 a^{2}}{4(2 a+1)^{2}}>0$ $\Leftrightarrow a<\frac{1}{2}+\frac{1}{2} \sqrt{2}$ and when $\frac{7}{64}-\frac{3}{32} a>0 \Leftrightarrow a<\frac{7}{6}$. For $a \in\left[\frac{7}{6}, \frac{1}{2}+\frac{1}{2} \sqrt{2}\right]$, the respective interval for $U$ becomes $\left[0, \frac{4 a+1-4 a^{2}}{4(2 a+1)^{2}}\right)$. For $a>\frac{1}{2}+\frac{1}{2} \sqrt{2}$, case 2 a is not part of the optimal solution. 
Case 2b: $y_{2}=1$ which implies $y_{1}=0$. In this case, (23) yields $R=\beta+\frac{1}{2} a$. Then, (25) is satisfied for $U<-\frac{3}{32} a+\frac{7}{64}$. Again, when $\frac{7}{64}-\frac{3}{32} a<0$, then case $2 \mathrm{~b}$ is not part of the optimal solution. Finally note that since $\frac{4 a+1-4 a^{2}}{4(2 a+1)^{2}}>\frac{7}{64}-\frac{3}{32} a$; if $\max \left(0, \frac{4 a+1-4 a^{2}}{4(2 a+1)^{2}}\right)=0$, then the optimal solution stipulates $w_{I}^{*}>0$ for all $U$.

As for part iv), the worker earns at least his outside option and therefore always chooses to accept firm I's offer.

\section{Proof of Proposition 3}

The programming problem is identical to the one in the scenario without regulation, except that we have an additional constraint (22), which is also quasi-convex in $R$ and $w_{I}$. Denoting the respective multiplier by $y_{3}$, the Lagrangian is

$$
\begin{aligned}
Z & =\left(1-\frac{a-R+\beta}{4 a}\right) \cdot \beta+\left(\frac{a-R+\beta}{4 a}\right) \cdot R-w_{I} \\
& -y_{1}\left(-w_{I}+\left(\frac{a-R+\beta}{16 a^{2}}\right)(a(2(R-\beta+a)-3)-R+\beta)\right) \\
& +y_{2} w_{I}-y_{3}\left[R-w_{I}\right]
\end{aligned}
$$

for which the respective Kuhn-Tucker conditions are

$$
\begin{aligned}
\frac{\partial Z}{\partial R} & =0 \\
\frac{\partial Z}{\partial w_{I}} & =0 \\
-U & \geq-w_{I}+\left(\frac{a-R+\beta}{16 a^{2}}\right)(a(2(R-\beta+a)-3)-R+\beta) \\
0 & \geq-w_{I} \\
\bar{r} & \geq R-w_{I} \\
y_{1}, y_{2}, y_{3} & \geq 0 \\
0 & =y_{1}\left[w_{I}-\left(\frac{a-R+\beta}{16 a^{2}}\right)(a(2(R-\beta+a)-3)-R+\beta)-U\right] \\
0 & =y_{2} w_{I} \\
0 & =y_{3}\left[\bar{r}-R-w_{I}\right]
\end{aligned}
$$


When $w_{I}>0$ it follows from (37) that $y_{2}=0$ must hold. Thus we have to consider 3 cases: Case 1 (which explains part i) of the Proposition): $y_{1}=0$ and therefore $y_{3}=1$. In this case, from (30) we get $R^{*}=\beta-\frac{3}{2} a>0$ (by Assumption 1) and from (38), $w_{I}^{*}=\beta-\frac{3}{2} a-\bar{r}$ and thus, $r^{*}=\bar{r}$ holds. From the participation constraint we have

$$
\begin{array}{r}
-U+w_{I}^{*}-\left(\frac{a-R^{*}+\beta}{16 a^{2}}\right)\left(\left(a\left(2\left(R^{*}-\beta+a\right)-3\right)-R^{*}+\beta\right)\right) \geq 0 \Leftrightarrow \\
\beta-\frac{43}{32} a+\frac{15}{64}-\bar{r} \geq U .
\end{array}
$$

Case 2: $y_{1}>0$ and $y_{3}>0$ : For this case, (30), (31), (36) and (38) must hold simultaneously, so that we have 4 equations for 4 endogenous variables $\left(R, w_{I}, y_{1}, y_{3}\right)$ with solution $R^{*}=\rho, w_{I}^{*}=\rho-\bar{r}, y_{1}^{*}=2 a \frac{2 \rho-2 \beta+3 a}{2 \rho a-\rho-2 \beta a-a+\beta+8 a^{2}}, y_{3}^{*}=$ $\frac{2 \beta a-a+\beta+2 a^{2}-2 \rho a-\rho}{2 \rho a-\rho-2 \beta a-a+\beta+8 a^{2}}$ where

$$
\begin{aligned}
\rho(U)= & \frac{a-8 a-\beta+2 \beta a}{-1+2 a} \\
& +\left(\frac{2}{-1+2 a}\right) \sqrt{a^{2}\left(4(U+\bar{r})(2 a-1)+17 a^{2}-8 \beta a-6 a+4 \beta+1\right)} .
\end{aligned}
$$

One calculates that $y_{1}$ is strictly increasing in $\rho$, so that $y_{1}>0 \Leftrightarrow \rho>\beta-\frac{3}{2} a>$ 0 while $y_{3}$ is strictly decreasing in $\rho$ so that $y_{3}>0 \Leftrightarrow \rho<\beta+\frac{a(2 a-1)}{2 a+1}=R^{J}$. Using the definition for $\rho$, this can be transformed into a condition in $U$ for which one gets

$$
\begin{aligned}
\rho(U) & \in\left(\beta-\frac{3}{2} a, \beta+\frac{a(2 a-1)}{2 a+1}\right) \Leftrightarrow \\
U & \in\left(\beta-\frac{43}{32} a+\frac{15}{64}-r, \frac{16 a(\beta(a+1)+a(a-\bar{r})-\bar{r})+4\left(\beta-\bar{r}-a^{2}\right)+1}{4(2 a+1)^{2}}\right)
\end{aligned}
$$

Finally, we have $w_{I}>0 \Leftrightarrow U>\frac{2 r \beta-\beta^{2}-\bar{r}^{2}-a\left(2\left(a^{2}+\bar{r}-\bar{r}^{2}-\beta+2 \bar{r} \beta-\beta^{2}\right)-3 a\right)}{16 a^{2}}$.

Case 3: $y_{1}=1$ and thus $y_{3}=0$ : In this case, (30) and (36) must hold with equality, which yields $R^{*}=\beta+\frac{a(2 a-1)}{2 a+1}=R^{J}$ and $w_{I}^{*}=\frac{4(a(a+4 U(a+1)-1)+U)-1}{4(2 a+1)^{2}}$ which is strictly increasing in $U$ and therefore positive for $U>\frac{4 a+1-4 a^{2}}{4(2 a+1)^{2}}$ so that the condition becomes $U>\max \left(0, \frac{4 a+1-4 a^{2}}{4(2 a+1)^{2}}\right)$ Moreover, (34) is satisfied 
when

$$
\begin{aligned}
w_{I}^{*} & \geq R^{*}-\bar{r} \Leftrightarrow \\
U & \geq \frac{16 a(\beta(a+1)+a(a-\bar{r})-\bar{r})+4\left(\beta-\bar{r}-a^{2}\right)+1}{4(2 a+1)^{2}} .
\end{aligned}
$$

\section{E Proof of Proposition 4}

The optimization problem is the same as in Proposition 3, where here we analyze under which circumstances the optimal contract stipulates $w_{I}^{*}=0$. We have to consider the following three cases:

Case 1: $y_{1}=0, y_{2} \geq 0$ and $y_{3}>0:$ In this case, one has to solve the equation system with Eqns. (30), (31) and (38) for three endogenous variables $\left(R, y_{2}, y_{3}\right)$ which yields $R=\bar{r}, y_{2}=\frac{1}{4} \frac{3 a-2 \beta+2 \bar{r}}{a}$, and $y_{3}=\frac{1}{4} \frac{2 \beta+a-2 \bar{r}}{a} . y_{2}$ is strictly increasing in $\bar{r}$ and therefore non-negative for $\bar{r} \geq-\frac{3}{2} a+\beta>0$ while $y_{3}$ is strictly decreasing in $\bar{r}$ and positive for $\bar{r}<\frac{1}{2} a+\beta$. To check for which levels of $U$ this is consistent with $w_{I}^{*}=0$ and condition (32), substitute $R^{*}$ and $w_{I}^{*}=0$ in (32) to yield $U \leq \frac{2 \bar{r} \beta-\beta^{2}-\bar{r}^{2}-a\left(2\left(a^{2}+\bar{r}-\bar{r}^{2}-\beta+2 \bar{r} \beta-\beta^{2}\right)-3 a\right)}{16 a^{2}}$.

Case 2: $y_{1}>0, y_{2} \geq 0$, and $y_{3}=0$ : For this case, the equation system to solve consists of Eqns. (30), (31) and (36) for three endogenous variables $\left(R, y_{1}, y_{2}\right)$ which leads to solution $R^{*}=\phi, y_{1}=2 a \frac{2 \beta+a-2 \phi}{\phi+2 \beta a+a-\beta-2 \phi a}$, and $y_{2}=\frac{2 \phi a+\phi-2 \beta a+a-\beta-2 a^{2}}{\phi+2 \beta a+a-\beta-2 \phi a}$ where

$$
\phi(U)=\frac{1}{2(-1+2 a)}\left(2 a-2 \beta+4 \beta a-4 \sqrt{\left(a^{2}-4 U a^{2}-2 a^{3}+8 U a^{3}+a^{4}\right)}\right)
$$

Substituting this into $y_{1}$ and $y_{2}$ reveals that $y_{1}>0 \Leftrightarrow U>\frac{7}{64}-\frac{3}{32} a$ and that $y_{2} \geq 0 \Leftrightarrow$ $U \leq \frac{4 a+1-4 a^{2}}{4(2 a+1)^{2}}$. Thus, this region is part of the optimal contract if $\frac{7}{64}-\frac{3}{32} a>0$. Moreover, we have $\phi\left(U=\frac{7}{64}-\frac{3}{32} a\right)=\beta+\frac{1}{2} a$ and $\phi\left(U=\frac{4 a+1-4 a^{2}}{4(2 a+1)^{2}}\right)=\frac{2 \beta a-a+\beta+2 a^{2}}{2 a+1}=R^{J}$. Finally, we have to determine the levels of $U$ for which (32) is also satisfied: Solving $\bar{r}-R^{*} \geq 0$ for $U$ yields $U \geq \frac{2 \bar{r} \beta-\beta^{2}-\bar{r}^{2}-a\left(2\left(a^{2}+\bar{r}-\bar{r}^{2}-\beta+2 \bar{r} \beta-\beta^{2}\right)-3 a\right)}{16 a^{2}}$ as stated in the Proposition. As in the case without regulation, this region exists only if $\frac{7}{64}-\frac{3}{32} a>0$.

Case 3: $y_{1}=0, y_{2}=1$, and $y_{3}=0$ : For this last case, (30) yields $R^{*}=\beta+\frac{1}{2} a$. Since this case is only relevant for $\bar{r} \geq \beta+\frac{1}{2} a$, condition (34) is trivially satisfied. For (32), substituting $R^{*}$ and $w_{I}^{*}=0$ yields $U \leq \frac{7}{64}-\frac{3}{32} a$. Again, if $\frac{7}{64}-\frac{3}{32} a<0$ then this regions 
does not exist.

\section{F Proof of Proposition 5}

Given the continuation game as established by Propositions 3 and 4, the regulator maximizes expected social welfare with respect to $\bar{r}$. As for part i), as long as $w_{I}^{*}=0$ holds on the equilibrium path, $R^{F}=-a+\beta$ can be achieved by simply setting $\bar{r}=R^{F}$. The threshold value for $U$, for which this is no longer possible is determined by setting $\bar{r}=R^{F}$ in the equation according to which is $w_{I}^{*}=0$ holds (see Proposition 4 , case 1 ), i.e.

$$
U=\frac{2 R^{F} \beta-\beta^{2}-\left(R^{F}\right)^{2}-a\left(2\left(a^{2}+R^{F}-\left(R^{F}\right)^{2}-\beta+2 R^{F} \beta-\beta^{2}\right)-3 a\right)}{16 a^{2}}
$$

which yields $U=\frac{1}{4}$. For $U>\frac{1}{4}$ and at $\bar{r}=R^{F}$ we are no longer in region $B 1$ but in region $A 2$ (see Proposition 3, part ii)). Also in this case, $R^{F}$ can be implemented as long as $U$ is not too high: Setting $\rho$ as given above equal to $R^{F}$ and solving for $U$ yields $\bar{r}^{*}=R^{F}+\frac{1}{4}-U$. Thus, the maximum level of $U$ for which $R^{F}$ can be implemented by a non-negative $\bar{r}$ is $U=R^{F}+\frac{1}{4}$. For all $U>R^{F}+\frac{1}{4}$, we are still in region $A 1$ so that the worker's participation constraint will be binding. This means that even for $\bar{r}=0$ we already have $w_{I}^{*}>R^{F}$ and thus the best the regulator can do is not increasing $R$ even further by choosing $\bar{r}=0$. That the resulting level of $R$ is strictly lower than $R^{J}=\beta+\frac{a(2 a-1)}{2 a+1}$ follows from the fact that $R^{J}-\beta=a \frac{2 a-1}{2 a+1}>0$ and the initial Assumption that $\beta>\bar{U}$.

\section{References}

Aghion, P., and P. Bolt on (1987): "Contracts as a Barrier to Entry," American Economic Review, 77(3), 388-401.

Arrow, K. J., and A. C. Ent hoven (1961): "Quasi-concave Programming," Econometrica, (October), 779-800. 
Bal kenbor g, D. (2001): "How Liable Should a Lender Be? The Case of JudgmentProof Firms and Environmental Risk: Comment," American Economic Review, 91(3), $731-738$.

Burguet, R., R. Caminal, and C. M at ut es (2001): "Golden Cages for Showy Birds: Optimal Switching Costs in Labour Markets," European Economic Review, forthcoming.

Chung, T.-Y. (1992): "On the Social Optimality of Liquidated Damage Clauses: An Economics Analysis," Journal of Law, Economics $\mathcal{G}$ Organization, 8(2), 280-305.

— (1995): "On Strategic Commitment: Contracting versus Investment," American Economic Review, 85(2 (May)), 437-441.

Diamond, P., and E. M a skin (1979): "An Equilibrium Analysis of Search and Breach of Contract, I: Steady State," Bell Journal of Economics, 10, 282-316.

F eess, E., and G. M uehI heusser (2002): "Transfer fee regulations in European football," IZA Discussion Paper, No. 423.

Myerson, R., and M. Sat terthwait e (1983): "Efficient Mechanisms for Bilateral Trading," Journal of Economic Theory, 29, 265-81.

Posner, E. A., and G. G. Triant is (2001): "Convenants Not to Compete From an Incomplete Contracts Perspective," Chicago Law School Working Paper No. $13 \%$.

Rogerson, W . P. (1984): "Efficient reliance and damage measures for breach of contract," RAND Journal of Economics, 15(1), 37-53.

Rubin, P. H., and P. Shedd (1981): "Human Capital and Convenants Not to Compete," Journal of Legal Studies, 10, 93-110.

Schw eizer, U . (1999): "Robust Possibility and Impossibility Results," mimeo, University of Bonn.

Shavel I, S. (1980): "Damage Measures for Breach of Contract," Bell Journal of Economics, 11, 466-490. 
Spier, K ., and M. W hinst on (1995): "On the efficiency of privately stipulated damages for breach of contract: entry barriers, reliance, and renegotiation," RAND Journal of Economics, 26(2), 180-202. 